\title{
The Along-Wind Diffusion of the Tracer Cloud in Finite Release Experiments
}

\author{
by \\ Junji Sato \\ Meteorological Research Institute, Tsukuba, Ibaraki, 305 Japan
}

(Received October 6, 1988 ; Revised January 19, 1989)

\begin{abstract}
The along-wind elongation of the tracer plume was observed in the medium-range atmospheric diffusion experiments with finite release time of air tracer substance. Since the elongated portion of a detached plume pursues the same course in the treatment of along-wind diffusion as an instantaneous puff, the along-wind diffusion paramenter $\sigma_{x}$ was estimated from the time variation of concentration in the elongated portion of the detached plume. This was compared with $\sigma_{x}$ from other equivalent range experiments after grouping under stable, near neutral, and unstable classifications of atmospheric stability. In stable codition, a slight tendency to smaller $\sigma_{x}$ values was recognized, but distinct dependency of $\sigma_{x}$ growth on stability was not observed.

Furthermore, consideration was taken of the valuation of time average concentration relating to the tracer release time, sampling time, and total time of tracer cloud passage. The method of evaluating the average concentration was considered, and it was made clear that the method was available for any sampling mode.
\end{abstract}

\section{Introduction}

The major atmospheric diffusion experiments conducted up to the present were designed to measure crosswind and vertical diffusion, so relatively scant data exist describing the along-wind diffusion. This may partly be due to the greater interest in the continuous plume in which along-wind diffusion may be neglected. Furthermore, several atmospheric diffusion experiments were also designed to adopt a period of around one hour for the release time of tracer substance as, for example, reported by Islizer (1961), McElroy (1969), and Emberlin (1981), etc..

In atmospheric diffusion experiments with finite release time of the air tracer, sulfur hexafluoride, $\mathrm{SF}_{6}$, is an air tracer widely used. However, this tracer provides only concentration averaged over the time interval from when the dispersing tracer arrives at sampling point to when the last part of the tracer passes. Since it is difficult to measuring the instantaneous concentration of $\mathrm{SF}_{6}$ continuously, these time intervals are estimated from data of wind speed. In most of data analysts of diffusion experiments, one had to assume some elapsed time interval in order to obtain the average concentration, and this time interval was assumed to be equal to release time. This assumption seems not to be so clear excepting relatively shorter release time, so we need to reconsider the method which one has used to obtain time average concentration in diffusion experiments with finite release time.

Analyzing the data by time-sequential samplers located several kilometers downwind of the source showed that the total time required for the passage of a detached plume was not always equal to the release time of the tracer. This implied that the detached plume was elongated along with the wind direction. The 
detached plume means a finite length tracer cloud which is released from a point source in finite releasing time.

In the past Japan Environment Agency made field experiments of atmospheric diffusion of medium range up to $10 \mathrm{~km}$ distance downwind. Those experiments were conducted at 10 littoral industrialized areas in Japan during the 6 yeats from 1967 to 1972 under the environmetal assessment program. Meteorolog. ical Research Institute participated in these experiments, and the analysis in the present paper is made with the data of these experiments. Although the point source experiments with finite release time of the fluorescent particle tracer used in this analysis were not always designed to measure along-wind diffusion, in addition to extensive ground surface exposure measurements, two time-sequential samplers located several kilometers downwind from the source were available. The time-sequential sampling data least provided the arrival time and passage time of the tracer cloud, and time variation of concentration. These data permit the estimating of the along-wind diffusion parameter $\sigma_{\mathrm{x}}$ from elongated portion of detached plume.

In this paper, we will discuss the following two subjects: one is the evaluation of alongwind diffusion parameter $\sigma_{\mathrm{x}}$ in comparison with other data obtained from several experiments of equivalent scale, and the other average concentration related to the length of sampling time in a detached plume, this being not well known. Lately the latter problem has become a specially interested subject in the analysis of diffusion experiments of finite release.

\section{Elongation of the Tracer Cloud in Finite Release}

Previous to analysis, we picked out the only data which is the tracer plume striking the time-sequential sampling point. These data did not contain the meandering of the tracer plume. Furthermore, additional extraction was made on the data, the only data which is position of the center of crosswind distribution of concentration to be around the time-sequential sam- pling point were selected as seen in Fig. 1. These data provided sufficient information to make a detailed analysis of the time variation of one-minute exposure (or one-minute average concentration). The brief summary of extracted experiments in the present analysis is given in Table 1. All experiments were conducted in the daytime in a coastal region, the sources were placed near the coast, the sampling networks were spread onshore, and the samplers were set at $1.5 \mathrm{~m}$ above the ground surface. The details of individual sampling networks were shown by Sakuraba et al. (1969) and Sato (1973).

Remarkable elongation is found in Test
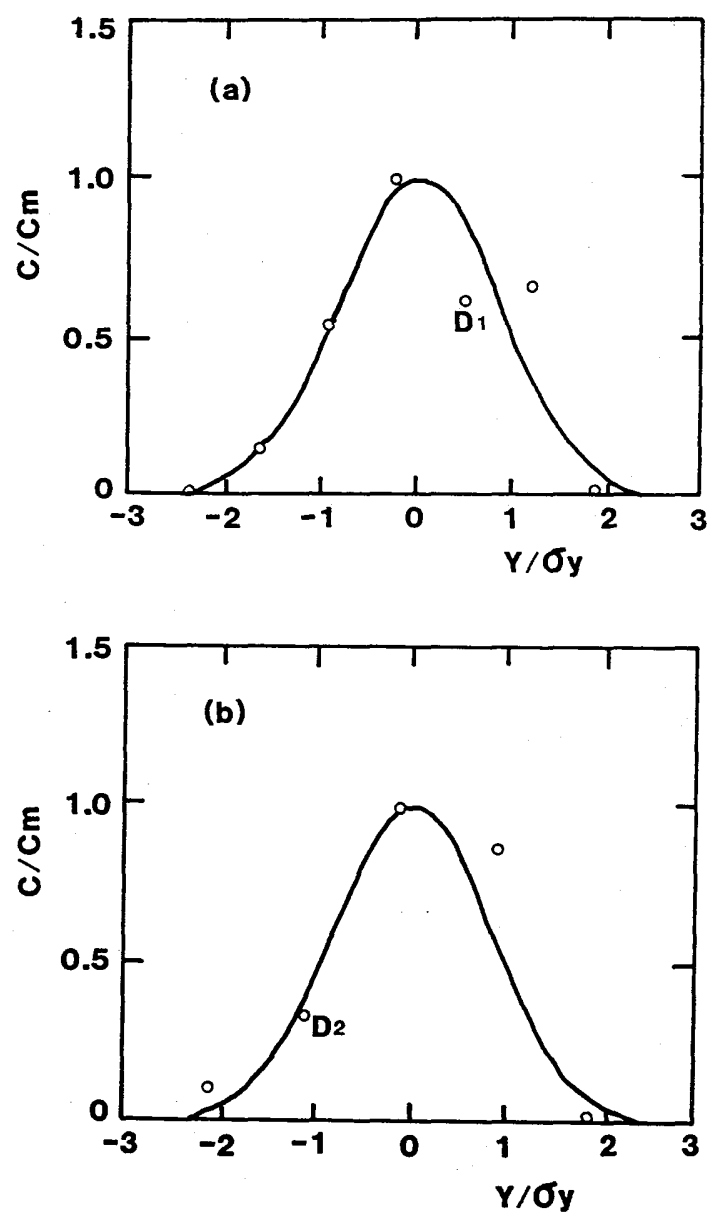

Fig. 1 The location of the time-sequential sampling $\left(\mathrm{D}_{1}, \mathrm{D}_{2}\right)$ on the crosswind distribution of concentration for Test W1. (a) is at $x=1.5 \mathrm{~km},(\mathrm{~b})$ at $x=5.0 \mathrm{~km}$. 
Table 1 Summary of extracted data used for analysis.

\begin{tabular}{|c|c|c|c|c|c|c|c|}
\hline Test & & Date & $\begin{array}{l}\text { Release } \\
\text { time } \\
\text { From To }\end{array}$ & $\begin{array}{l}\text { Source } \\
\text { height } \\
(\pi)\end{array}$ & $\begin{array}{l}\text { Downwind } \\
\text { distance } \\
(\mathrm{km})\end{array}$ & $\begin{array}{l}\text { Travel } \\
\text { time } \\
\text { (min) }\end{array}$ & $\begin{array}{l}\text { EXcess } \\
\text { elongation } \\
\quad(\text { min) }\end{array}$ \\
\hline$M 2$ & 8 & Aug. 1967 & $12: 30-13: 00$ & 90 & 3.40 & 29.0 & 22.0 \\
\hline $\begin{array}{l}\text { T2 } \\
\text { T4 } \\
\text { T5 } \\
\text { T5 }\end{array}$ & $\begin{array}{l}25 \\
27 \\
27 \\
27\end{array}$ & $\begin{array}{ll}\text { July } & 1968 \\
\text { July } & 1968 \\
\text { July } & 1968 \\
\text { July } & 1968\end{array}$ & $\begin{array}{l}15: 00-15: 28 \\
11: 00-11: 30 \\
13: 00-13: 30 \\
13: 00-13: 30\end{array}$ & $\begin{array}{l}150 \\
150 \\
150 \\
150\end{array}$ & $\begin{array}{l}2.50 \\
2.50 \\
2.50 \\
5.15\end{array}$ & $\begin{array}{l}49.0 \\
13.5 \\
42.5 \\
72.5\end{array}$ & $\begin{array}{l}32.0 \\
23.0 \\
15.0 \\
26.0\end{array}$ \\
\hline $\begin{array}{l}\text { W1 } \\
W 1 \\
W 2 \\
W 3 \\
W 5 \\
W 6\end{array}$ & $\begin{array}{l}7 \\
7 \\
8 \\
8 \\
9 \\
9\end{array}$ & $\begin{array}{ll}\text { Aug. } 1968 \\
\text { Aug. } 1968 \\
\text { Aug. } 1968 \\
\text { Aug. } 1968 \\
\text { Aug. } 1968 \\
\text { Aug. } 1968\end{array}$ & $\begin{array}{l}12: 01-12: 27 \\
12: 01-12: 27 \\
12: 30-13: 00 \\
12: 30-13: 00 \\
12: 30-13: 00 \\
12: 30-13: 00\end{array}$ & $\begin{array}{r}200 \\
200 \\
5 \\
200 \\
5 \\
200\end{array}$ & $\begin{array}{l}1.50 \\
5.00 \\
1.50 \\
5.00 \\
1.50 \\
1.50\end{array}$ & $\begin{array}{l}24.0 \\
66.0 \\
10.0 \\
30.0 \\
16.0 \\
15.0\end{array}$ & $\begin{array}{r}22.0 \\
46.0 \\
6.0 \\
13.0 \\
19.0 \\
20.0\end{array}$ \\
\hline $\begin{array}{l}\text { S2 } \\
\text { S2 }\end{array}$ & $\begin{array}{l}27 \\
27\end{array}$ & $\begin{array}{ll}\text { July } & 1969 \\
\text { July } & 1969\end{array}$ & $\begin{array}{l}14: 11-14: 30 \\
14: 11-14: 30\end{array}$ & $\begin{array}{l}200 \\
200\end{array}$ & $\begin{array}{l}3.00 \\
7.30\end{array}$ & $\begin{array}{l}14.0 \\
84.0\end{array}$ & $\begin{array}{l}19.0 \\
15.0\end{array}$ \\
\hline $\begin{array}{l}01 \\
01 \\
02 \\
02 \\
03 \\
06\end{array}$ & $\begin{array}{l}25 \\
25 \\
25 \\
25 \\
26 \\
27\end{array}$ & $\begin{array}{ll}\text { Aug. } & 1969 \\
\text { Aug. } & 1969 \\
\text { Aug. } 1969 \\
\text { Aug. } 1969 \\
\text { Aug. } 1969 \\
\text { Aug. } 1969\end{array}$ & $\begin{array}{l}14: 00-14: 30 \\
14: 00-14: 30 \\
14: 00-14: 30 \\
14: 00-14: 30 \\
10: 30-11: 00 \\
10: 00-10: 30\end{array}$ & $\begin{array}{r}5 \\
5 \\
150 \\
150 \\
150 \\
5\end{array}$ & $\begin{array}{l}2.60 \\
4.70 \\
2.60 \\
4.70 \\
4.70 \\
2.60\end{array}$ & $\begin{array}{r}11.0 \\
41.5 \\
11.0 \\
46.5 \\
70.5 \\
9.5\end{array}$ & $\begin{array}{r}10.0 \\
21.0 \\
10.0 \\
31.0 \\
13.0 \\
9.0\end{array}$ \\
\hline $\begin{array}{l}\text { N1 } \\
\text { N2 } \\
\text { N2 } \\
\text { N3 } \\
\text { N6 }\end{array}$ & $\begin{array}{l}7 \\
8 \\
8 \\
8 \\
8\end{array}$ & $\begin{array}{l}\text { Aug. } 1972 \\
\text { Aug. } 1972 \\
\text { Aug. } 1972 \\
\text { Aug. } 1972 \\
\text { Aug. } 1972\end{array}$ & $\begin{array}{l}16: 07-16: 30 \\
10: 00-10: 30 \\
10: 00-10: 30 \\
10: 40-11: 10 \\
15: 30-16: 00\end{array}$ & $\begin{array}{l}100 \\
200 \\
200 \\
100 \\
200\end{array}$ & $\begin{array}{l}6.95 \\
3.15 \\
6.95 \\
3.45 \\
6.95\end{array}$ & $\begin{array}{l}63.5 \\
41.0 \\
66.0 \\
23.0 \\
77.5\end{array}$ & $\begin{array}{l}27.0 \\
27.0 \\
24.0 \\
10.0 \\
13.0\end{array}$ \\
\hline
\end{tabular}

W1, which shows that the detached tracer plume grows up about 1.8 times longer than release time at $x=1.5 \mathrm{~km}$ and 2.7 times longer at $x=5.0 \mathrm{~km}$. Fig. 2 shows the time variation of one-minute exposure as an instance, and the shadowed portion corresponds with the time interval equal to tracer release. Here, we defined the elongation $\left(D_{x}\right)$ as $D_{x}=T_{p}-\tau$, where $T_{p}$ is the total time required for the passage of the detached plume and $\tau$ the release time. Even though along-wind diffusion is often neglected in the diffusion equation for an infinite continuous plume, along-wind diffusion effect will be important if concentration fluctuates in the continuous plume. On the other hand, in the case of a detached plume, along-wind diffusion effect comes out at the front and rear edges of the plume as in the case of the instantaneous puff. Gifford (1959) considered that the real smoke plume may regarded as superposition of individual elementary puffs. This idea leads to a puff model to simulate the concentration distribution of air pollutants. Zannetti (1981) discussed the puff method in simulating the plume behavior, and noted that the puff method was applicable to both non-stationary and non-homogeneous conditions, as well as calm wind situations.

The problem of concentration fluctuation in a continuous plume has been discussed by 


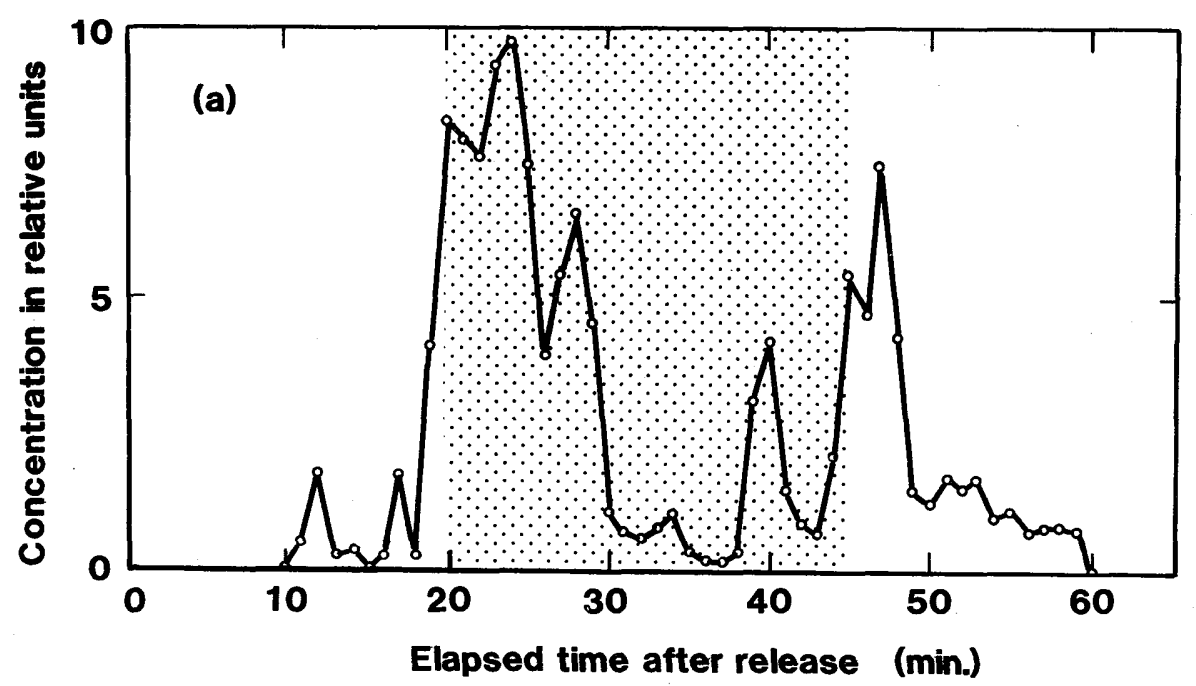

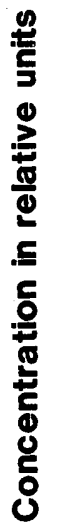

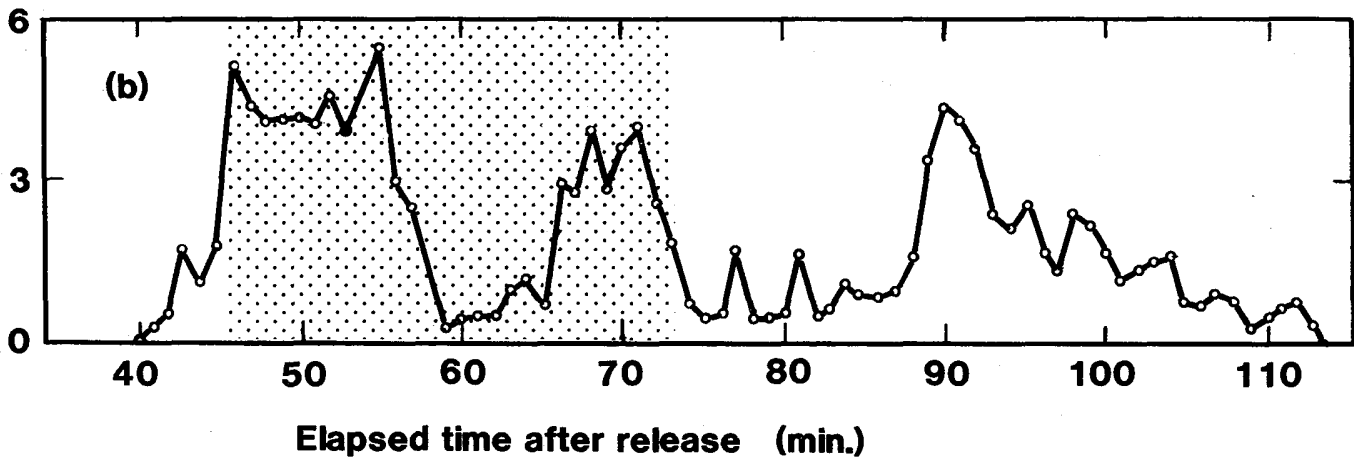

Fig. 2 The time variation of one-minute average concentration of the detached plume for Test W1. The shadowed portion is the time interval equal to release time. (a) is at $x=1.5 \mathrm{~km}, \quad$ (b) at $x=5.0 \mathrm{~km}$.

Wilson (1982), Kimura et al. (1983), and Hanna (1984) etc., so we will fix our attention on the edge effect of a detached plume from the viewpoint of along-wind diffusion.

In the case of Test W1, remarkable elongation was seen at the rear portion of the tracer plume. Such the phenomenon seems to be originated not only in turbulence caused by vertical wind shear but also in the extreme change of wind speed during the release of the tracer. Furthermore, the leakage of the remaining tracer from weaks of air current, behind obstacles such as houses or groves must be one of causes of elongation. It is very difficult to evaluate the leakage quantitatively, so we assumed that the leakage effect can be ignored in the present analysis because a large majority of the present experiments take an elevated source. So far we have made an analysis of extreme elongation by taking transport wind speed into consideration. According to the time-sequential sampler data (see Fig. 2), the transport speed of the front edge of the tracer cloud from $x=0 \mathrm{~km}$ to $x=1.5 \mathrm{~km}$ is $2.3 \mathrm{~m} / \mathrm{sec}$, while that of the rear edge is $0.8 \mathrm{~m} / \mathrm{sec}$.

As half-hourly pilot ballon observations 

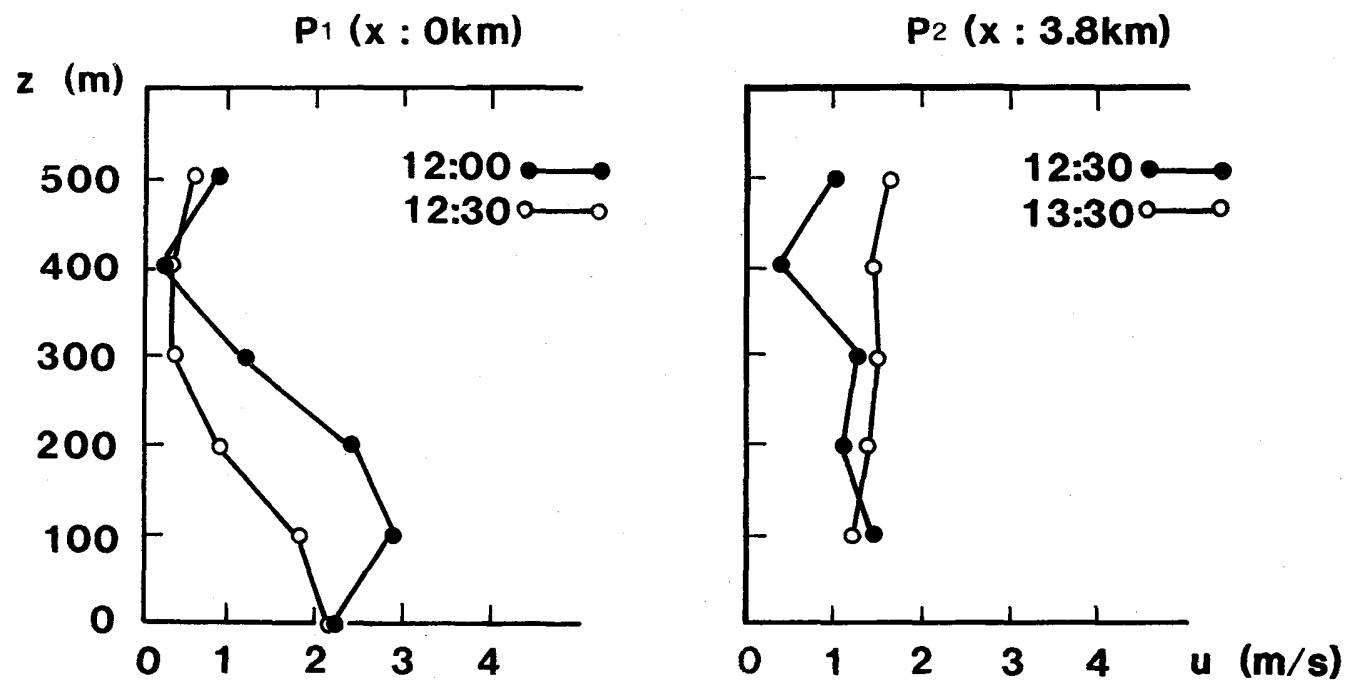

Fig. 3 Wind speed profiles by pilot balloon observations for Test W1.
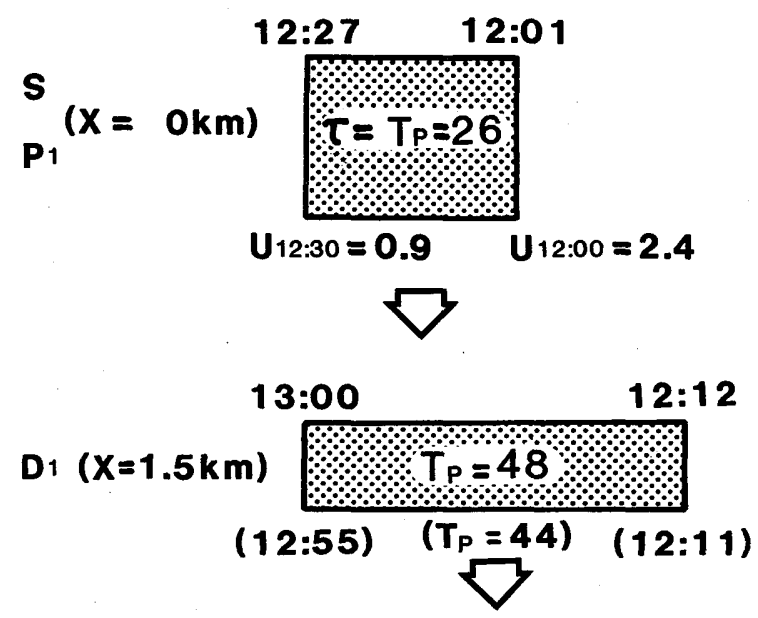

(13:37)

(12:27)

$P_{2}(X=3.8 \mathrm{~km})$

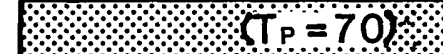

$U_{13: 30}=1.3$

$U_{12: 30}=1.3$
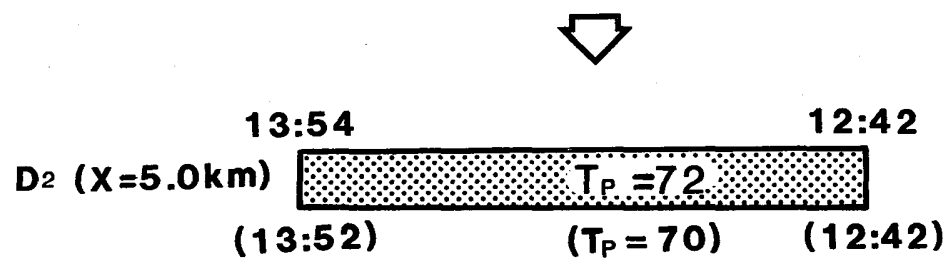

Fig. 4 Schematic drawing of tracer cloud transport process for Test W1. 
were carried out at $x=0 \mathrm{~km}\left(\mathrm{P}_{1}\right)$ and $x=3.8 \mathrm{~km}$ $\left(\mathrm{P}_{1}\right)$, we can compare the transport speed of the tracer and the wind speed obtained from pilot balloon observations. Fig. 3 shows the wind speed profiles for Test $\mathrm{W} 1$ at $\mathrm{P}_{1}$ and $\mathrm{P}_{2}$, and Fig. 4 schematically shows the transport process of an elongating tracer cloud. We will compare the tracer transport spreed with the pilot balloon data. If frontal tracer cloud flows by a wind speed of $2.4 \mathrm{~m} / \mathrm{sec}$ (at $z=200 \mathrm{~m}$ ), it will reach $\mathrm{D}_{1}(x=1.5 \mathrm{~km})$ at $12: 11$, and $\mathrm{P}_{2}$ at 12 : 27. The corresponding arrival time of the rear of the tracer cloud is $12: 55$ at $\mathrm{D}_{1}$, and $13: 37$ at $\mathrm{P}_{2}$. The calculated passage time of the tracer cloud $\left(T_{p}\right)$ is 44 minutes at $\mathrm{D}_{1}$, while the observed $T_{p}$ is 48 minutes as seen from Fig. 4. From $\mathrm{P}_{2}$ on, the transport speed of the front edge estimated from the pilot balloon data is $1.1 \mathrm{~m} /$ $\mathrm{sec}$, and that of the rear edge is $1.3 \mathrm{~m} / \mathrm{sec}$, so the arrival time of the front edge at $\mathrm{D}_{2}$ is around 12:45, and that of the rear adge is 13:52. Then the calculated $T_{p}$ becomes 67 minute, while the observed $T_{p}$ is 72 minutes. All the exposures were measured at the ground level, so it is necessary to employ mean wind speed

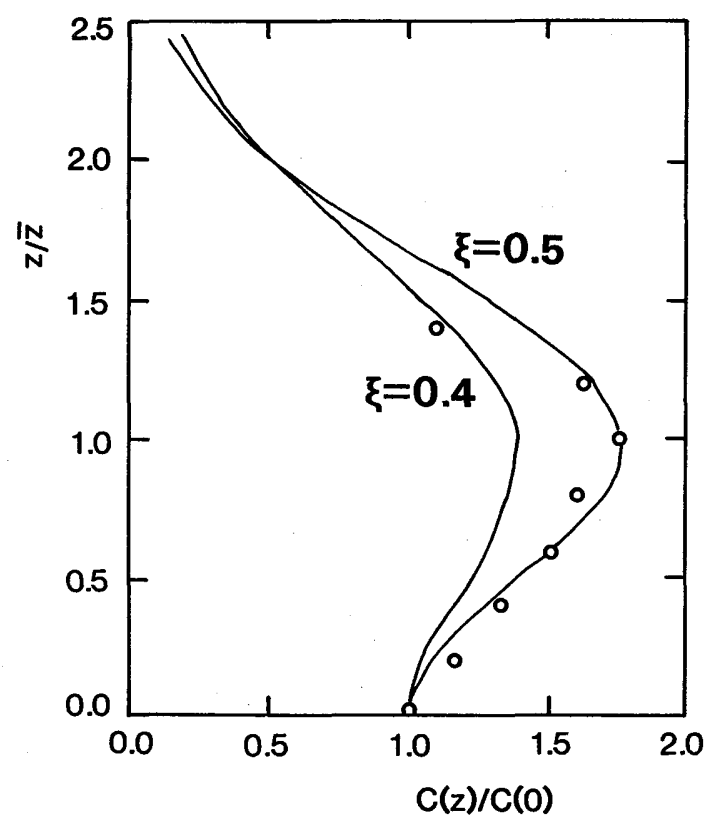

Fig. 5 Relative concentration profile observed at $x=1.5 \mathrm{~km}$ for Test W1. $\xi=$ $\sigma_{z} / \bar{z}$, and $\bar{z}$ means plume centerline height. below the plume centerline height. Fig. 5 shows the observed profile of relative concentration at $x=1.5 \mathrm{~km}$. As seen in Fig. 5, it is clear that the plume centerline height, $\bar{z}$, at $x=1.5 \mathrm{~km}$ is almost the same as the tracer release height $(200 \mathrm{~m})$. The averaged wind speeds below $z=$ $200 \mathrm{~m}$ at $\mathrm{P}_{2}$ are about $1.3 \mathrm{~m} / \mathrm{sec}$ near the front and rear edges of plume passing through at 12 : 30 and 13:30, respectively.

By using the averaged wind, we can get $T_{p}=70$ minutes at $x=5.0 \mathrm{~km}$. The calculated $T_{p}$ is reasonable. From a standpoint of the horizontal scale of diffusion experiments up to $10 \mathrm{~km}$ or so, the temporal change of wind speed during the tracer may be due to a kind of large scale turbulence in the direction along the wind.

Csanady (1969) solved the diffusion equation with an effective diffusivity on the wind shear of the Ekman profile. According to this results Draxler (1979) expressd along-wind variance as

$$
\sigma_{x}^{2}=\sigma_{x t}^{2}+\sigma_{x \mathrm{~s}}^{2},
$$

where the turbulent contribution $\left(\sigma_{x t}\right)$ is given by

$$
\sigma_{x t}=3 T_{r} \overline{u^{\prime 2}} / \bar{u}^{2} \sim T_{r},
$$

where $u^{\prime}$ is the turbulent velocity component in the along-wind direction, $\bar{u}$ is the mean wind speed, and $T_{r}$ is the travel time. On the other hand, shear contribution $\left(\sigma_{x s}\right)$ is

$$
\sigma_{x s}=\frac{1}{u}\left(\frac{1}{25} \phi^{2} K_{z} T_{r}^{3}\right)^{1 / 2} \sim T_{r}^{3 / 2},
$$

where $\phi$ is the gradient of the wind speed profile, and $K_{z}$ is the vertical turbulent diffusivity. Eq. (2) was suggested by Smith and Hay (1961), and Eq. (3) by Suffman (1962). Eq. (3) including the term of vertical wind shear is appropriate for the diffusion of instantaneous release (puff), because most of the along-wind diffusion of a puff in shear flow is due to stretching of the tracer cloud by vertical wind shear except near the source where the puff is still so small. Nickola et al. (1970), Nickola (1971) and Sato et al. (1981) pointed out that the longitudinal concentration distribution showed a gradual decrease toward the rear of the puff, and this longitudinal diffusion is influenced by the stretching of the puff due to vertical wind shear 
(Wilson, 1981).

According to our analysis, the variation of tracer transport speed plays a dominant role in remarkable elongation rather than $d u / d z$ does. However, very close to both the edges of a detached plume, $d u / d z$ may be dominant for along-wind diffusion as in the case of an instantaneous puff. Therefore, we assumed that the elongated portion of a detached plume pursues the same course in the treatment of along-wind diffusion as a puff.

As it is very difficult to evaluate the contributions of shear and turbulence because of insufficiency of data, the along-wind diffusion parameter, $\sigma_{x}$, was calculated from the elongated portion of a detached plume as seen in Fig. 6 . $\sigma_{x}$ is compared with data from three other diffusion experiments of appropriate range discussed by Draxler (1979). The three experiments had the instantaneous line sources of fluorescent particles (FP) generated by an aircraft passing parallel to the sampling line. The Victoria experiment consisted of 17 offshore releases of FP from $90 \mathrm{~m}$ height near Corpus Christi, Texas. The Oceanside experiment was conducted along the California coast between Oceanside and Del Mar, the aircraft releases were made several kilometers offshore and most were at a height of about $60 \mathrm{~m}$ similar to the Victoria. On the other hand, the Fort Wayne experiment was conducted at a moderately industrialized city (Fort Wayne, Indiana) surrounded by flat farmland. Two separated instantaneous line releases were made at 91 and $214 \mathrm{~m}$ in height. The details of the individual experiment were given by Draxler (1979). A comparison is shown in Fig.7, where line 1 means the summary of Fort Wayne data, line 2 is Victoria, and line 3, Oceanside. The black dots and black square are the results from the source near the ground surface (about $5 \mathrm{~m}$ above), and the other are from elevated sources $(100-200 \mathrm{~m})$. The stability categories employed were subjectively defind from the lapse rate of temperature profile in ${ }^{\circ} \mathrm{C} / \mathrm{m}$ as follows:

- stable $\cdots \cdots \cdot d T / d z<-10 \times 10^{-3}$

- near neutral …. $-10 \times 10^{-3}$

$$
<d T / d z<-5 \times 10^{-3}
$$

- unstable $\cdots \cdots-5 \times 10^{-3}<d T / d z$.

A tendency for $\sigma_{x}$ value in stable condition to be smaller is slighty seen but strong dependency of $\sigma_{x}$ growth rate on stabiliy is not clear as

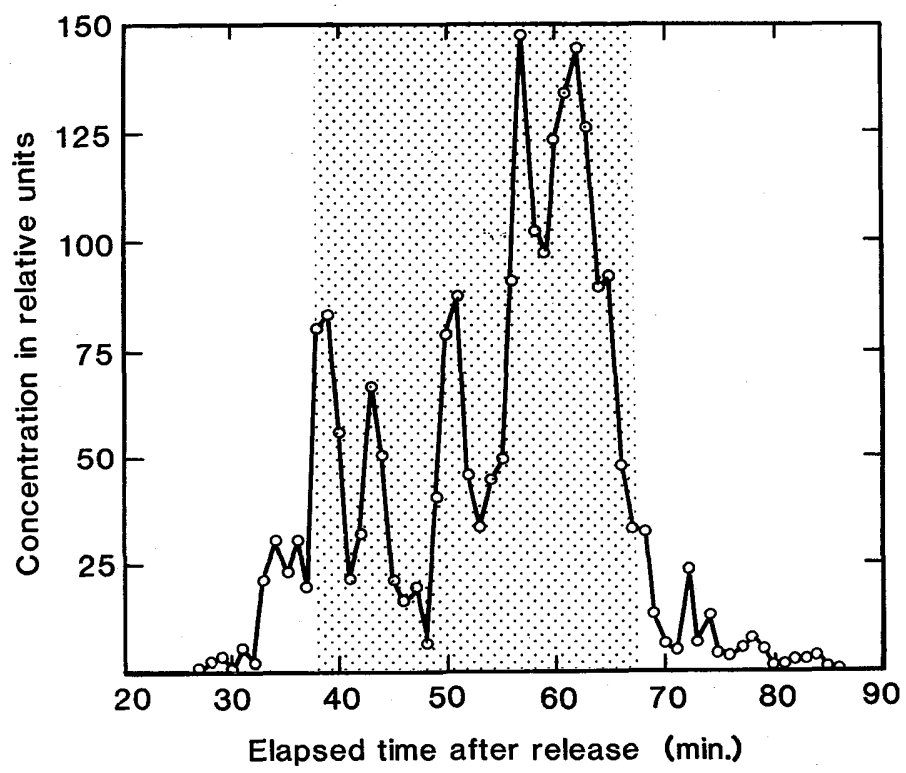

Fig. 6 Time variation of one-minute average concentration of the detached plume for Test N2. The shadowed portion is time interval equal to release time. $(x=3.45 \mathrm{~km})$. 
in Fig. 7.

\section{Average Concentration in a Detached Plume}

The concentration usually expressed in the diffusion equation is usually the instantaneous concentration, $\mathrm{C}$. Measurements of $\mathrm{C}$ are very difficult in practical fields because of lack of a sufficient number of samplers required for such measurements. Therefore, most of the diffusion experiments involved measurements of exposure rather than average concentration. The exposure is the integral of the concentration over a specified time interval.

$$
\psi=\int_{T_{0}}^{T_{0}+T} C d t
$$

where $T$ refers to the sampling time defined as the time during which samplers are actuated.

The average concentration over the sam pling time, $\bar{C}(\mathrm{~T})$, is obtained by dividing $\psi$ by $T$

$$
\bar{C}(T)=\frac{1}{T} \int_{T_{\mathrm{o}}}^{T_{\mathrm{o}}+T} C d t .
$$

The solution of the diffusion equation for a continuous point source is expressed by

$$
\frac{U}{Q} C(x, y, z)=\frac{1}{2 \pi \sigma_{y} \sigma_{z}} F(y) \cdot G(z, \bar{z}),
$$

where $Q$ is the source strength, $\sigma_{y}(x)$ and $\sigma_{z}$ $(x)$ are the standard deviations of concentration distribution for crosswind and vertical directions, respectively, and $\bar{z}$ is the elevation of the plume centerline.

The continuity condition for Eq. (6) is

$$
\int_{0}^{\infty} \int_{-\infty}^{\infty} u C d y d z=Q \text {. }
$$

Most of finite release diffusion analyses were made on the assumption that $T=\tau$, and average concentration is

$$
\bar{C}(\tau)=\frac{1}{\tau} \int_{T_{0}}^{T_{0}+\tau} C d t .
$$

Though $\tau=T_{p} \leq T$ is the only condition to satisfy the continuity in this case, the condition of $\tau=T_{p}$ is dependent on tne reality because the along-wind diffusion is disregarded. We will

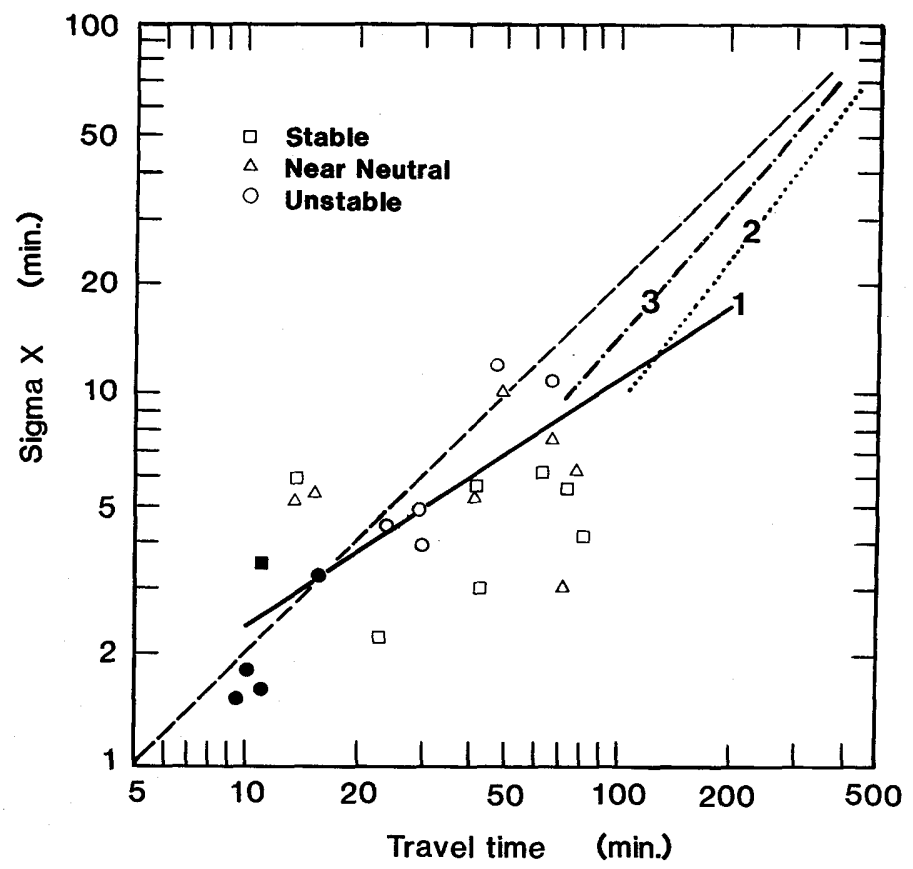

Fig. 7 Summary of along-wind diffusion of the detached tracer plume. 
refer to the case of the detached tracer plume which is applicable in a great portion of field studies of atmospheric diffusion.

The equation of mass continuity is

$$
\int_{T_{0}}^{T_{0}+T_{p}} \int_{0}^{\infty} \int_{-\infty}^{\infty} u C d y d z d t=Q \tau
$$

where $Q \tau$ shows the total mass of the released tracer.

Divided by $T_{p}$, Eq. (9) becomes

$$
\int_{0}^{\infty} \int_{-\infty}^{\infty} \overline{u C} d y d z=\frac{\tau}{T_{p}} Q \equiv Q^{\prime}
$$

where

$$
\overline{u C}=\frac{1}{T_{p}} \int_{T_{\mathrm{o}}}^{T_{\mathrm{o}}+T_{\mathrm{p}}} \stackrel{u}{u} C d t \approx \bar{u} \bar{C}\left(T_{p}\right)
$$

\section{1) The case of $T \geq T_{p}$}

In the detached plume, it is generally $\tau<$ $T_{p}$, so two sampling modes may be considered; one is the case of $T \geq T_{p}>\tau$, the other is $T_{p}>$ $T>\tau$. Hereafter we will denote the former by $T>T_{p}$, and the latter by $T<T_{p}$.

First, we will discuss the case of $T \geq T_{p}$ shown in Fig. 8 (b). This corresponds to the case where the whole detached plume has been included in the duration of sampling; namely, the samplers are actuated since the time when the detached tracer plume arrived at the sampling points until it completely passed away.

The Eq. (10) becomes

$$
\int_{0}^{\infty} \int_{-\infty}^{\infty} \overline{u C}(T) d y d z=\frac{\tau}{T} Q=Q^{\prime} .
$$

The diffusion equation corresponding to Eq. (11) should be

$$
\frac{\bar{u} \bar{C}(T)}{Q^{\prime}}=\frac{T}{\tau} \cdot \frac{\bar{u} \bar{C}(T)}{Q}=\frac{1}{2 \pi \sigma_{y} \sigma_{z}} \cdot F(y) \cdot G(z, \bar{z}) .
$$

As known from Eq. (11), the source intensity corresponding to the average concentration $\bar{C}(T)$ is not $Q$ but $Q^{\prime} . Q$ is coincident with $Q^{\prime}$ only when $T=\tau$.

In order to simplify Eq. (12) we introdece a provisional concentration $C^{\prime}$, defind as $C^{\prime}=C$ $T / \tau$; then the exposure becomes

$$
\psi=\int_{T_{0}}^{T_{0}+T} C d t=\int_{T_{0}}^{T_{0}+\tau} C^{\prime} d t,
$$

and the corresponding average concentration $\bar{C}(\tau)$ is

$$
\bar{C}(\tau)=\frac{1}{\tau} \cdot \int_{T_{0}}^{T_{0}+\tau} C^{\prime} d t=\frac{1}{\tau} \cdot \int_{T_{0}}^{T_{0}+\tau} \frac{T}{\tau} C d t .
$$

Eq. (12) becomes

$$
\frac{\bar{u} \bar{C}(\tau)}{Q}=\frac{1}{2 \pi \sigma_{y} \sigma_{z}} \cdot F(y) \cdot G(z, \bar{z}) .
$$

As mentioned above, even if the detached tracer plume elongated to the along-wind direction $\left(T_{p}>\tau\right)$, it becomes clear that the time averaged relative concentration in the case of $T \geq T_{p}$ is also expressed by the diffusion equation for $T_{p}=\tau$.
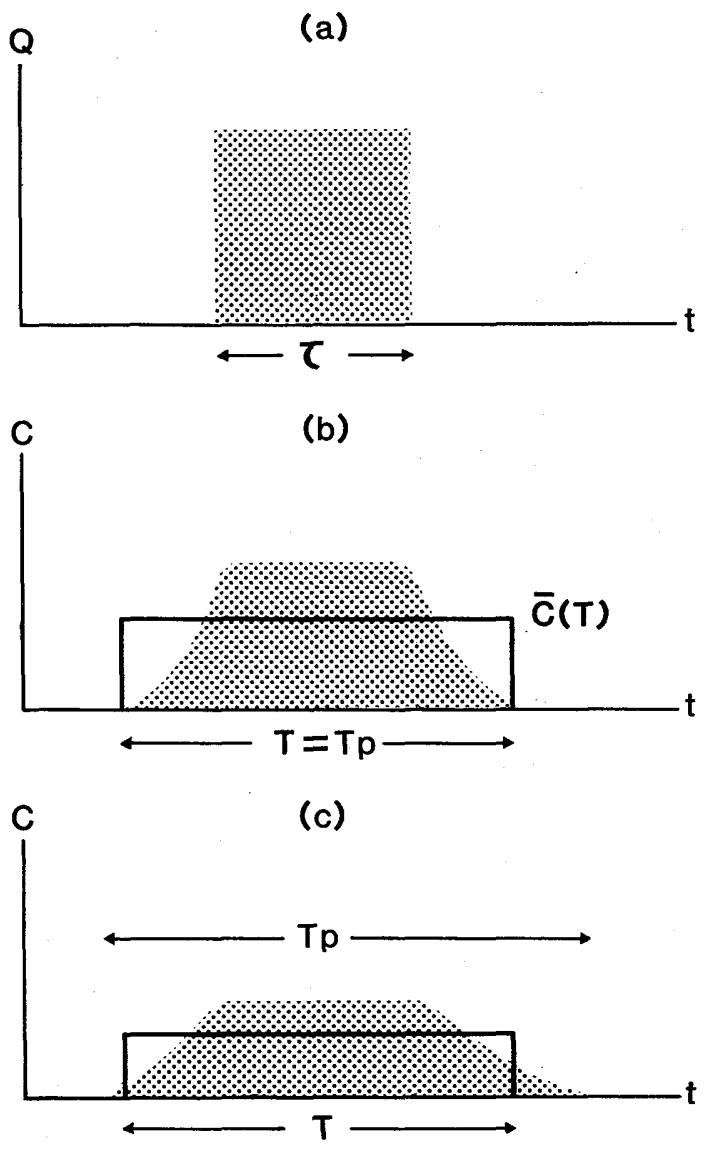

Fig. 8 Schematic drawing of the relation between sampling time and elongating detached plume. 


\section{2) The case of $T<T_{p}$}

Next, we will examine the case of $T<T_{p}$ shown in Fig. 8 (c). This is a rather rare case, and occurs when the sampling time does not cover the whole range of the passage time in consequence of remarkable elongation of along-wind direction.

We may write as

$$
\int_{T_{0}}^{T_{0}+x} u C d t \simeq \frac{T}{T_{0}} \int_{T_{0}}^{T_{0}+T_{p}} u C d t=T \overline{u C} .
$$

Then, the best estimation for the equation of mass continuity in this case is

$$
T \int_{0}^{\infty} \int_{-\infty}^{\infty} \overline{u C} d y d z=\frac{T}{T_{p}} Q \tau,
$$

which yields

$$
\frac{T_{p}}{\tau} \frac{\vec{u} \bar{C}(\tau)}{Q}=\frac{1}{2 \pi \sigma_{y} \sigma_{z}} \cdot F(y) \cdot G(z, \bar{z}) .(16)
$$

Eq. (16) represents the corrected average concentration in the case of $T<T_{p}$.

\section{Concluding Remarks}

Elongation of the detached plume in the along-wind direction was observed from the time variation of concentration in diffusion experiments with finite release time of air tracer. From a standpoint of along-wind diffusion, a consideration of time average concentration in an elongating detached plume was also made relating to sampling time and passage time of the detached tracer plume. The results are summarized as follows:

(1) On the correlation between stability and the growth rate of $\sigma_{x}$ with downwind distance, general dependency was not evident. Though it is not clear because of insufficient data, the following reasons are considered:

- The stability was defind only from temperature profiles.

- The change of wind speed during the release of the tracer also plays a part. But it is not connected with stability.

In the calculation of $\sigma_{x}$, the definition of the elongated portion $\left(D_{x}\right)$ in fluctuating concentration was made as $D_{x}=T_{p}-\tau$, the time period corresponding to $\tau$ was subjectively taken. It was adapted from relative high concentration observed for the first time in the series of fluctuating concentration as seen in Fig. 6 .

(2) In the diffusion experiment with finite release time of the air tracer, the average concentration must be corrected referring to sampling time as follows:

- In the case of $T>T_{p}, \bar{C}(T)$ may be expressed by Eq. (12) and $\bar{C}(\tau)$ by Eq. (14).

- In the case of $T<T_{p}, \bar{C}(\tau)$ made by Eq. (16).

To obtain the average concentration, we observed the time variation of concentration (or length of detached plume for along-wing direction). In the field diffusion experiment with finite release, the air tracer substance whose instantaneous concentration or sequential short time dosage must be used for determination of $T_{p}$. A successful sampling mode was adopted as $T>\tau+D_{x} ; \mathrm{D}_{x}$ was determined from the previous estimation of the range of wind spend variation. In the case of a tracer substance such as $\mathrm{SF}_{6}$, the uncomplicated sampling mode is $T \ll \tau$, and it is approximately continuous release.

Acknowledgment:- The author wishes to express his hearty thanks to the staff members of the Applied Meteorology Research Division of the Meteorologial Research Institute for useful discussions.

\section{References}

Csanady, G. T., 1969: Diffusion in an Ekman layer. J. Atmos. Sci., 26, 14-26.

Draxler, R. R., 1979: Some observations of the along-wind dispersion parameter. Preprints of "Fourth Symposium on Turbulence, Diffusion and Air Pollution", 5-8.

Emberlin, J. C., 1981: A sulfur hexafluoride tracer experiment from a tall stack over complex topography in a coastal area of Southern England. Atmos. Environ., 15, 1523-1530.

Hanna, R. S., 1984:The exponential probability density function and concentration flactuations in smoke plumes. Bounday-Lager Met., 29, 361-379.

Gifford, F., 1959: Statistical properties of a fluctuating plume dispersion model. Advances in Geo- 
physics., 6, 117-137.

Islizer, N. F., 1961: Short-range atmosphericdispersion measurements from an elevated source. Journal of Meteor., 18, 443-450.

Kimura, F., T. Yoshikawa, and J. Sato, 1981: Frequency distribution of concentration on the center of mean plume axis in the surface layer. Pap. Met. Geophys., 32, 149-154.

MacElroy, J., 1969: A comparative study of urban and rural dispersion. J. Appl. Met ., 8, 19-31.

Nickola, P. W., J. D. Ludwick and J. V. Ramsdell, Jr., 1970: An inert gas tracer system for monitoring the real-time history of a diffusing plume or puff. J. Appl. Met., 9, 621-626.

Nikola, P. W., 1971: Measurements of the movement, concentration and dimensions of clouds resulting from instantaneous point source. J. Appl. Met., 10, 962-973.

Saffman, P. J., 1962: The effect of wind shear on horizontal spread from an instantaneous ground source. Quart. J. Roy. Met. Soc., 88,
382-393.

Sakuraba, S., M. Moriguchi and I. Yamazi, 1969: A comparative study of surface-source dispersion and elevated-source dispersion. Pap. Met. Geophys., 20, 337-364.

Sato, J., 1973: The vertical spread of concentration in a stable layer. Pap. Met. Geophys., 24, $413-433$.

Sato, J., F. kimura and T. Yoshikawa, 1981: The longitudinal spread of puff in the short range diffusion experiment. Pap. Met. Geophys., 32, 155-162.

Smith, F. B. and J. S. Hay, 1961: The expansion of clusters particles in the atmosphere. Quart. J. Roy. Met. Soc., 87, 898-91.

Wilson, D. J., 1981: Along-wind diffusion of source transients. Atmospheric Environment., 15, 489-495.

Wilson, D. J., 1982: Predicting the spatial distribution of concentration fluctuation from a ground level source. Atmos. Environ., 16, 221-259.

\section{トレーサー実験における有限長プルームの主軸方向の拡散}

\section{佐藤純次}

エア・トレーサーを有限時間に放出した中規模大気拡散実験において，トレーサープルームが風下方向に引き 伸ばされる現象が観測された。このような有限長プルームの引き伸ばされた部分は，トレーサーを瞬間的に放出 したパフの拡散の場合と同じであると仮定することによって $x$ 方向の拡散パラメー夕, $\sigma_{x}$ 求めることができる。 有限長プルームから求めた $\sigma_{x}$ 「安定」,「ほぼ中立」「「不安定」の 3 階級の大気安定度に分類し, 他の類似した

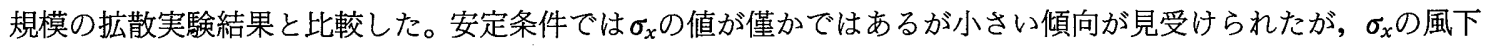
方向への変化に対する安定度の影響は認められなかった。

さらに，連続条件を満足するようにトレーサーの放出時間，サンプリング時間，トレーサープルームの長さを 考慮した時間平均濃度を適性に評価する方法を検討した。この方法はいかなるサンプリングモードにも適用でき る。 